\title{
Relative Merits of Selected Anthropometric Measurements for Detecting Protein-Energy-Malnutrition (PEM) in Children Under Five Years in a Resource Limited Setting
}

\author{
Hamed Ademola Adetunji ${ }^{1 *}$, Gafaar Sola Salami², Mohamed Salih El Fadil', Mohammed Shamim ${ }^{3}$, Tabrez Uz \\ Zaman', Mohammed Bakri' ${ }^{4}$, Khalil Mohamed ${ }^{1}$, Mohamed Osman Elamin Bushara ${ }^{3}$
}

\begin{abstract}
Hamed Ademola Adetunji,*, Gafaar Sola Salami², Mohamed Salih El Fadil ${ }^{1}$, Mohammad Shamim³, Tabrez Uz Zaman ${ }^{4}$, Mohammed Bakri' ${ }^{1}$ Khalil Mohamed', Mohamed Osman Elamin Bushara ${ }^{3}$ 'Department of Epidemiology, Faculty of Public Health and Health Informatics, Umm Al Qura University, Makkah, SAUDI ARABIA.

${ }^{2}$ Department of Special Education, University of Ibadan, Ibadan, NIGERIA. ${ }^{3}$ Department of Health Promotion and Education, Faculty of Public Health and Health Informatics, Umm Al Qura University, Makkah, SAUDI ARABIA. ${ }^{4}$ Department of Health Information Technology and Management, Faculty of Public Health and Health Informatics, Umm Al Qura University, Makkah, SAUDI ARABIA.
\end{abstract}

\section{Correspondence}

Prof. Hamed Ademola Adetunji

Department of Epidemiology, Faculty of Public Health and Health Informatics, Umm Al Qura University, 21955, Makkah, SAUDI ARABIA.

Mobile no: +966 556264196

Email: hamed.tunji@gmail.com

History

- Submission Date: 17-11-2018.

- Revised Date: 29-04-2019;

- Accepted Date: 29-10-2019;

DOI : 10.5530/ijmedph.2019.4.33

Article Available online

http://www.ijmedph.org/v9/i4

\section{Copyright}

(C) 2019 Phcog.Net. This is an openaccess article distributed under the terms of the Creative Commons Attribution 4.0 International license.

\begin{abstract}
In order to find out the most sensitive anthropometric measurement that will diagnose Protein Energy Malnutrition (PEM) in Nigerian pre-school children, three hundred children between the ages of 12 and 60 months (100 each of Normal, PEM and other malnutrition) were measured for height, weight, upper-arm circumference, triceps skinfold and subscapular skinfold thickness. The results showed that Triceps skinfold is the most sensitive anthropometric indicator for diagnosis of PEM in the study population. This supports the hypothesis that energy deficiency may be a more predominant factor in the causation of PEM in Nigeria.

Key words: Protein-Energy-Malnutrition, Under-five, Anthropometric measurement,
\end{abstract}

Developing countries, Resource restricted.

\section{INTRODUCTION}

Malnutrition, especially that affecting young children, is one of the principal public health problems in large areas of the world today. The importance of malnutrition as an obstacle to social and economic development and as a conditioning factor in a wide range of diseases is being increasingly recognised. It has been observed that special nutritional requirements of children have made them particularly vulnerable to malnutrition. Malnutrition has also been identified as one the most essential risk factor for the burden of disease in developing countries according to Murray and Lopez ${ }^{1}$ and Nemer et al. ${ }^{2}$ It is also reported that malnutrition is a direct cause of nearly 300000 deaths each and is indirectly accountable for around half of all deaths in young children by Food and Agriculture Organisaion, ${ }^{3}$ Nemer et al. ${ }^{2}$ Müller ${ }^{4}$ and also Black, Morris and Bryce. ${ }^{5}$

Protein Energy Malnutrition (PEM) in children is recognised by 3 cardinal conditions namely underweight, stunted and wasting according to PinstrupAndersen et al. ${ }^{6}$ About $31 \%$, of all children under the age of 5 years in developing countries are underweight while $38 \%$ have stunted growth and $9 \%$ show wasting as found in by Brabin and Coulter.7 In developing countries, the classical picture of malnutrition presented statistically is of an iceberg. The actual situation is that when one case of severe malnutrition is presented in the clinics or in hospitals, it should be taken as in the general population; the actual number of moderate cases can range from 15-25 while mild cases may be between 25 and 35 as given by Norgan,
Bogin and Cameron. ${ }^{8}$ Malnutrition is diagnosed by anthropometric measurements and physical examination as suggested by Müller and Krawinkel. ${ }^{9}$ No other disease compares in importance with PEM in the field of Nutrition or Public Health. This is why early detection is very important to prevent complications.

Murray and Lopez, ${ }^{1}$ and Nemer et al. ${ }^{2}$ identified Malnutrition as one of the most essential risk factors for the burden of disease in developing countries. It is reported to be the direct cause of nearly 300,000 deaths each year and indirectly accountable for around half of all deaths in young children as documented by Food and Agriculture Organisaion, ${ }^{3}$ Nemer et al. ${ }^{2}$ Müller $^{4}$ and also Black, Morris and Bryce. ${ }^{5}$

Protein Energy Malnutrition (PEM) in children is recognised by three cardinal conditions namely underweight, stunted and wasting according to Pinstrup-Andersen et al. ${ }^{6}$ Brabin and Coulter ${ }^{7}$ found about $31 \%$, of all children under the age of 5 years in developing countries are underweight while $38 \%$ have stunted growth and $9 \%$ show wasting. In developing countries, the classical picture of malnutrition presented statistically is of an iceberg. The actual situation is that when one case of severe malnutrition is presented in the clinics or in hospitals, it should be taken as in the general population. As stated by Norgan, Bogin and Cameron, ${ }^{8}$ the actual number of moderate cases can range from 15-25 while mild cases may be between 25 and 35 . It is necessary to measure the nutritional status of a community to determine
Cite this article : Adetunji HA, Salami GS, Fadil MSE, Zaman UT, Bakri M, Khalil M, Bushara MEO. Relative Merits of Selected Anthropometric Measurements for Detecting Protein-Energy-Malnutrition (PEM) in Children Under Five Years in a Resource Limited Setting. Int J Med Public Health. 2019;9(4):154-9. 
the extent, severity, geographical distribution of malnutrition and to monitor the effectiveness of preventive programmes. Müller and Krawinkel ${ }^{9}$ suggested the use of anthropometric measurements and physical examination for the diagnosis of especially in children.

In spite of considerable efforts made by scientific workers, no single method has been found to be completely satisfactory. As a result, most workers use multiple indicators in their studies. Among the indicators suggested, include vital statistics, food consumption, clinical signs, laboratory tests and anthropometry. Lack of proper record keeping in most of the developing countries where malnutrition is common limits the usefulness of vital statistics in assessing the nutritional status. Food consumption study is cumbersome and difficult, while clinical signs and laboratory tests need highly qualified workers and expensive equipment that are not readily available in remote and rural settings of developing nations.

Of all the methods that have been employed for the assessment of nutritional status, anthropometric measurements are extensively used and have been reported to more effective as stated by Beaton et al. ${ }^{10}$ Nagy et al. ${ }^{11}$ Lohman et al. ${ }^{12}$ and Muella et al. ${ }^{13}$ documented height and weight; skinfold thicknesses (biceps, triceps, subscapular, suprailiac, thigh) and circumferences (relaxed arm, flexed upper arm, waist, hip, upper thigh) as the most commonly used Anthropometric measurements. Part of the usefulness of anthropometric measurements is that it can be rendered into indices of fat mass, fat-free mass and their distribution in the human body according to Nagy et al. ${ }^{11}$ Selections of anthropometric measurements are somewhat arbitrary, but the degree to which the measurements reflect environmental changes and their practicability, reliability and sensitivity usually determine the selection. On broad basis, anthropometric measurements can be categorised into three groups - the weight that assesses body mass, the height that assess linear dimensions, skinfold thickness and the mid-arm circumference that assess body composition and reserves of energy and protein as judged by the principal superficial soft tissues - subcutaneous fat and muscle.

FAO/WHO Committee on Nutrition ${ }^{14}$ suggested long time ago the need for development of simple, objective 'Nutritional Indicators' that can be used by general public health workers with limited knowledge of Nutrition for detecting malnutrition in the community. Anthropometric measurements carried out by healthcare staff were found to be cheap, noninvasive and gives excellent information on the different constituents of body structure, in particular the muscular and fat components and can be of immense value to evaluate the nutritional status of a population Baumgartner. ${ }^{13}$ Since measurements of all indices are, time consuming and uneconomical, it is desirable to find out the simple most useful anthropometric indicator for Energy Protein Malnutrition (PEM) in the pre-school children. The present study aimed to find out the comparative usefulness of various indicators for detection of PEM in Nigerian pre-school children and to determine the best single anthropometric indicator for detection of PEM. The results will be useful in other resourcerestricted countries like Nigeria.

\section{MATERIALS AND METHODS}

The study population consisted of 300 pre-school children of ages between 1 and 5 years. They were from the outpatient departments of both the University College Hospital and Oni Memorial Paediatric Hospital in Ibadan, the capital of Oyo State, Nigeria. Clinical examination and anthropometric evaluation of the trend of nutritional status of the children were carried out after the verification of their ages from the records as contained in their hospital cards. Ethical panels of both hospitals approved the research and the data collected after the informed consent.

All mothers of the children who participated were interviewed using a structured pre-coded questionnaire. The questionnaire contained four main sections designed to obtain personal information of the child; socio-economic information; anthropometry (the Height [HT], body Weight [WT], Mid-Arm Circumference [MUAC], Triceps Skinfold Thickness [TSF] and sub-scapular skinfold thickness) and clinical examination which included the presence or absence of signs of malnutrition (hair depigmentation, pallor of conjunctiva, muscle wasting, oedema, angular lesion and angular scar). Each of the measurements made was standardised according to WHO specification and criteria. As per precision of measurements, height was taken to the nearest $0.1 \mathrm{~cm}$; body weight to the nearest $0.1 \mathrm{~kg}$; mid-arm circumference to the nearest 0.1 $\mathrm{cm}$; while the skinfold thickness was to the nearest $0.2 \mathrm{~mm}$.

\section{Clinical classification of children}

Children were categorised as belonging to one of the following groups: 1) Normal children -apparently normal without any nutritional deficiency sign and 2) Deficient children - having one or more signs of deficiency. Children in group 2 were further divided into 2 sub-groups: a) children with one or more signs of Protein Energy Malnutrition (PEM) and children with either anaemia or Vitamin B complex deficiencies. In addition, a child having one or more of the following was classified as being Vitamin deficient: angular lesion, angular scar and atrophic or hypertrophic lingual papillae. Pallor of the conjunctiva and nail were also examined to detect anaemia. Both the group in Vitamin deficient and that of anaemia were further grouped as group 3 - 'others'. The children in the study are therefore: Group 1 - Normal children; Group 2 - Protein Energy Malnutrition (PEM) children; Group 3 - Others (Vitamin deficient and children with anaemia).

\section{Statistical analysis}

Data analysis was through the SPSS. Descriptive statistics such as mean, median and standard deviation of all the anthropometric measurements were calculated for all groups. Pearson correlations were then calculated for each of the anthropometric variables to determine their inter-relationship. Student $(t)$ test was used to find out the significance of differences between the mean of various anthropometric measurements.

\section{RESULTS}

Table 1 shows the percentages of the children in the study according to their age in each group. Groups are Normal (group 1), PEM (group 2) and others (group 3 ). It shows that $47.6 \%$ of all the children in the study were within the ages of 12-23 months with the highest number 70 (49\%) in PEM group.

The mean values of height, weight, upper arm circumference, triceps skinfold thickness and subscapular skinfold measurement for the normal, PEM and others are presented in Tables 2. It reveals that the mean values of these variables (normal children in group 1 and others in group 3 are similar. The measurements in PEM (group 2) however, were significantly lower than those of normal and others. It can be seen also that the weight, subscapular and triceps skinfold were considerably affected while the height and upper arm circumference were slightly affected. Tables 3 and 4 display the student ' $t$ ' test and $p$-values of the anthropometric measurements when the Normal and 'others' are compared with PEM. Height and Subscapular are non-significant whereas PEM / Normal for weight $(6.2 p<0.001)$; UAC (3.2 $p<0.001)$; TSF $(6.9 p<0.001)$; and PEM / 'Others' for weight $(5.4 p<0.001)$; UAC $(3.2 p<0.001)$; TSF $(6.9 p<0.001)$; Table 5 displays the assessment of nutritional status of groups according to WT for age with reference to International Standards by $\mathrm{WHO}^{15}$ and Jelliffe. ${ }^{16}$ When the children were classified according to their weight for age, using Jellieffe ${ }^{16}$ standard, $47 \%$ of children in the 'normal' group had weight below $80 \%$ while $53 \%$ in 'others' group were below the cut off. However, more than $72 \%$ were found below this level in PEM group. To- 


\begin{tabular}{ccccc}
\multicolumn{4}{c}{ Table 1: Classification of pre-school children by age and group. } \\
$\begin{array}{c}\text { Age (in } \\
\text { months) }\end{array}$ & Group I & Group 2 & Group 3 & Total (\%) \\
\hline $12-23$ & 40 & 70 & 33 & $143(47.6)$ \\
$24-35$ & 20 & 16 & 32 & $68(22.7)$ \\
$36-47$ & 21 & 6 & 11 & $38(12.7)$ \\
$48-60$ & 19 & 8 & 24 & $51(17.0)$ \\
Total & 100 & 100 & 100 & $300(100)$
\end{tabular}

Table 3: Comparison of Mean and Standard Deviation of anthropometric measurements of children in Normal and PEM showing the significance levels.

$\begin{array}{cccccc}\text { Groups } & \text { HT } & \text { WT } & \text { UAC } & \text { TSF } & \text { SUBSCAP } \\ \text { Normal } & 86.2 \pm 10.7 & 10.7 \pm 3.5^{*} & 14.5 \pm 1.3^{*} & 7.8 \pm 2.0^{*} & 5.9 \pm 1.5 \\ \text { PEM } & 77.1 \pm 9.9 & 7.8 \pm 3.2^{* 0} & 12.4 \pm & 5.6 \pm 1.8^{* 0} & 4.3 \pm 1.2 \\ & & & 1.5^{* 0} & & \\ \text { Chi square } & \text { N/S } & (6.2 & (3.2 & (6.9 & \text { N/S } \\ \begin{array}{c}(p \text { value }) ; \\ \text { N/S }\end{array} & & p<0.001) & p<0.001) & p<0.001) . & \\ & & & & & \end{array}$

Data are mean \pm standard deviation.

\begin{tabular}{|c|c|c|c|c|c|}
\hline Groups & HT & WT & UAC & TSF & SUBSCAP \\
\hline Normal & $86.2 \pm 10.7$ & $10.7 \pm 3.5^{\star}$ & $14.5 \pm 1.3^{*}$ & $7.8 \pm 2.0^{*}$ & $5.9 \pm 1.5$ \\
\hline PEM & $77.1 \pm 9.9$ & $7.8 \pm 3.2^{\star \circ}$ & $\begin{array}{c}12.4 \pm \\
1.5^{\star \circ}\end{array}$ & $5.6 \pm 1.8^{\star \circ}$ & $4.3 \pm 1.2$ \\
\hline Others & $86.1 \pm 11.7$ & $10.5 \pm 3.6^{\circ}$ & $13.7 \pm 3.0^{\circ}$ & $7.3 \pm 1.8^{\circ}$ & $5.7 \pm 1.4$ \\
\hline
\end{tabular}

Data are mean \pm standard deviation.

Significantly different compared PEM with Normal \& 'Others': ${ }^{\star \circ} P<0.001$.

\begin{tabular}{|c|c|c|c|c|c|}
\hline Groups & HT & WT & UAC & TSF & SUBSCAP \\
\hline PEM & $77.1 \pm 9.9$ & $7.8 \pm 3.2^{\star \circ}$ & $\begin{array}{c}12.4 \pm \\
1.5^{\star 0}\end{array}$ & $5.6 \pm 1.8^{* \circ}$ & $4.3 \pm 1.2$ \\
\hline Others & $86.1 \pm 11.7$ & $10.5 \pm 3.6^{\circ}$ & $13.7 \pm 3.0^{\circ}$ & $7.3 \pm 1.8^{\circ}$ & $5.7 \pm 1.4$ \\
\hline $\begin{array}{c}\text { Chi square } \\
\text { ( } p \text { value); } \\
\text { N/S }\end{array}$ & $\mathrm{N} / \mathrm{S}$ & $\begin{array}{c}(5.4 \\
p<0.004)\end{array}$ & $\begin{array}{c}(3.2 \\
p<0.001)\end{array}$ & $\begin{array}{c}(5.4 \\
p<0.001)\end{array}$ & $\mathrm{N} / \mathrm{S}$ \\
\hline
\end{tabular}

Data are mean \pm standard deviation.

\begin{tabular}{|c|c|c|c|c|c|c|c|c|c|c|c|c|}
\hline \multicolumn{5}{|c|}{ Group 1 - Normal } & \multicolumn{4}{|c|}{ Group 2 - PEM } & \multicolumn{4}{|c|}{ Group 3 - Others } \\
\hline \multirow{2}{*}{$\begin{array}{c}\text { Age } \\
\text { (months) }\end{array}$} & \multirow{2}{*}{$\begin{array}{c}\text { No } \\
\text { Examined }\end{array}$} & \multicolumn{3}{|c|}{ Percentile } & No & \multicolumn{3}{|c|}{ Percentile } & \multicolumn{2}{|l|}{ No } & \multicolumn{2}{|c|}{ Percentile } \\
\hline & & 90 & 80 & $<60$ & Examined & 90 & 80 & $<60$ & Examined & 90 & 80 & $<60$ \\
\hline $12-23$ & 40 & 19 & 4 & 17 & 70 & 7 & 7 & 56 & 33 & 11 & 4 & 18 \\
\hline $24-35$ & 20 & 10 & 4 & 6 & 16 & 2 & 3 & 11 & 32 & 7 & 10 & 15 \\
\hline $36-47$ & 21 & 9 & 2 & 10 & 6 & - & 3 & 3 & 11 & 5 & - & 6 \\
\hline $48-60$ & 19 & 3 & 2 & 14 & 8 & 6 & - & 2 & 24 & 3 & 7 & 14 \\
\hline \multirow[t]{2}{*}{ Total } & 100 & 41 & 12 & 47 & 100 & 15 & 13 & 72 & 100 & 26 & 21 & 53 \\
\hline & & \multicolumn{3}{|c|}{59} & \multicolumn{4}{|c|}{85} & & & \multicolumn{2}{|c|}{74} \\
\hline
\end{tabular}

tal children below 90 Percentile cut off in 'normal' were 46\%, in 'others' $58 \%$ whereas in PEM $81 \%$.

Similarly, when the weight for height were used to assess the nutritional status of children (Table 6), $37 \%$ of the 'normal', $49 \%$ of other and $58 \%$ of PEM groups fell below $80 \%$ of the Standard Weight for Height. Total children below 90 Percentile cut off in 'normal' were 46\%, in 'others' $58 \%$ whereas in PEM 81\%.

When Upper Arm Circumference was compared (Table 7), 29\% of each of 'normal' and 'others' were found to be below $80 \%$ Standard while a considerably large number of children (75\%) from PEM fell below $80 \%$ of reference value. Overall, $40 \%$ each of 'normal' and 'others groups were below 90 percentile reference value whereas $83 \%$ from PEM fell below.

Assessment of the triceps skinfold thickness is presented in Table 8. In both the 'normal' and 'others', the results are similar with $60 \%$ and $67 \%$ children falling below $80 \%$ Standard whereas $92 \%$ fell below this level in the PEM group. Overall, nearly all (98\%) of children in PEM fell below $90 \%$ of standard.
Table 9 shows the frequency of diagnosis of malnutrition (80\% of reference value) in each group of children by various anthropometric measurements. The results show a large amount of misdiagnosis and or inaccurate diagnosis in case of apparently normal children (Table 9 column 1). For PEM group, WT for age, WT for HT and UAC were able to diagnose PEM with $81-87 \%$ accuracy. However, with triceps skinfold, the diagnosis was correct to about $98 \%$ level.

In 'others' the diagnosis was made more accurately in comparison with 'normal'. It thus appears from the data that largest errors in the diagnosis were made in 'Normal' group followed by 'others' and PEM groups in order. The data also showed that anthropometric variables are more sensitive for making diagnosis in PEM groups. Among anthropometric variable studied, triceps skinfold appears to be the most sensitive indicator for the diagnosis of PEM in this pre-school groups.

Tables 10 and 11 display the Pearson correlation between the anthropometric measurements in Normal, PEM and Others groups. In 'Normal' children, all anthropometric parameters (HT, WT, UAC, TST and Subscapular skinfold thickness were significantly correlated with each 


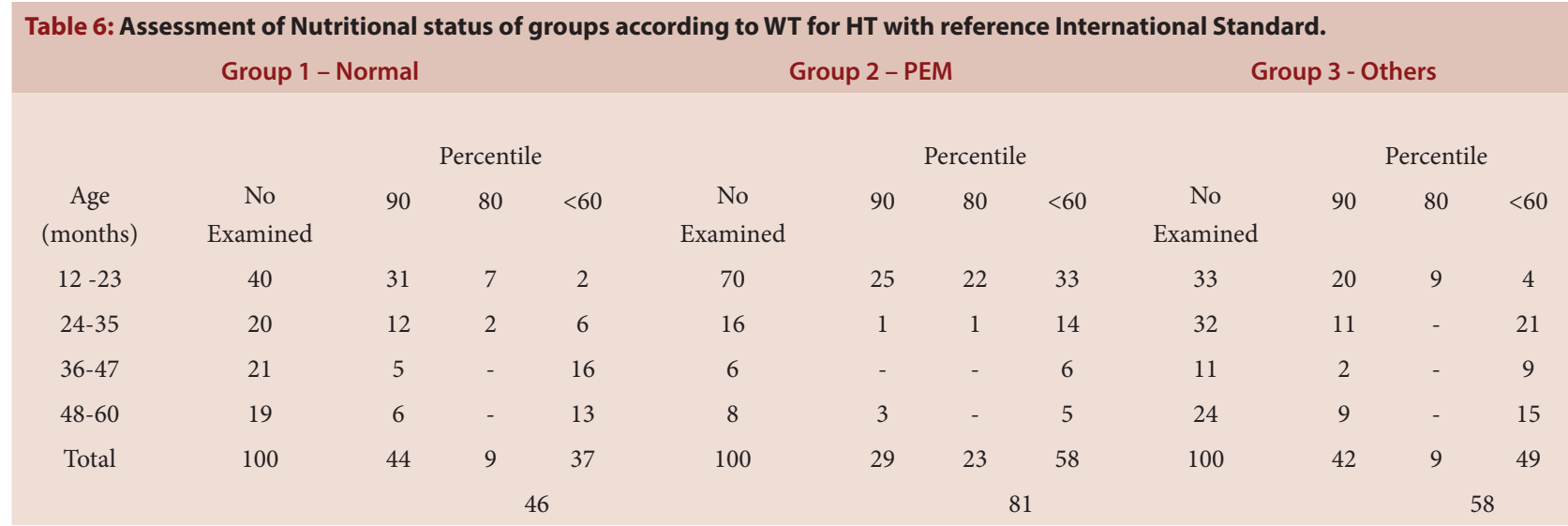

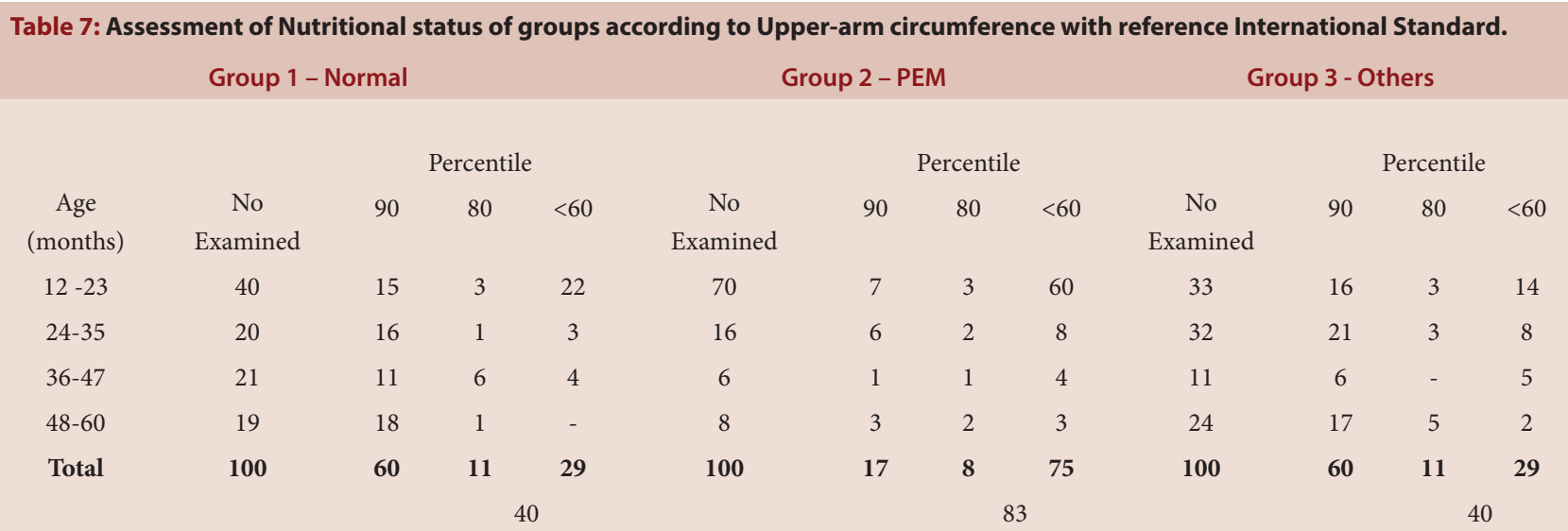

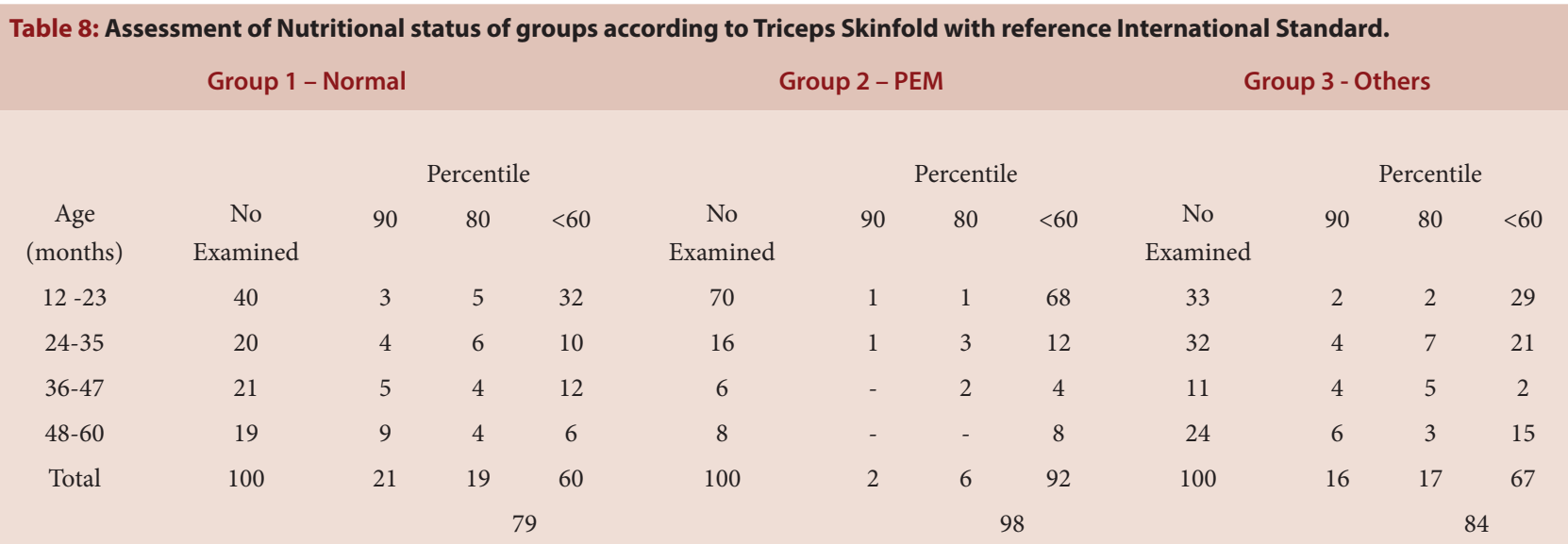

\begin{tabular}{|c|c|c|c|}
\hline Indices & Normal & PEM & Others \\
\hline TSF & 79 & 98 & 84 \\
\hline WT/AGE & 59 & 87 & 74 \\
\hline UAC & 40 & 83 & 40 \\
\hline WT/HT & 46 & 81 & 58 \\
\hline
\end{tabular}

Keys: TSF $=$ Triceps skinfold; $\mathrm{WT}=$ Weight UAC $=$ Upper Arm Circumference; HT=Height.
Table 10: Pearson correlation between the anthropometric measurements in PEM children.

$\begin{array}{ccc}\text { UAC versus SUBSCAP } & \text { TSF versus UAC } & \text { TSF versus SUBSCAP } \\ 0.49 p<0.001 & 0.27 p<0.003 & 0.26 p<0.004\end{array}$

Table 11: Pearson correlation between the anthropometric measurements in 'Others' children.

$\begin{array}{ccc}\text { UAC versus SUBSCAP } & \text { TSF versus UAC } & \text { TSF versus SUBSCAP } \\ 0.23 p<0.01 & 0.22 p<0.01 & 0.21 p<0.01\end{array}$


other, that means the growth is proportional. In the case of PEM children, the picture is different, this relationship changed significantly so that only subscapular skinfold thickness and UAC; TSF and subscapular skinfold thickness; and TSF and UAC were only significantly correlated. In 'Others' (Table 10), significant correlation between HT and WT $(p<0.001)$, HT and TSF $(p<0.001)$, WT and UAC $(p<0.01)$ and UAC and TSF $(p<0.001)$ were also found.

\section{DISCUSSION}

The present study examined the relative merits of anthropometric measurements in detection of PEM and their interrelationships in 'Normal' PEM and other malnourished children. The results of WT for age assessment, which is generally accepted as the simplest indicator of growth and nutrition according to Morley, ${ }^{17}$ showed that even in apparently normal group, $47 \%$ of these children, were below $80 \%$ of standard. This high percentage of under-weight in apparently normal children might probably be an indication that the $\mathrm{WHO}^{15}$ and Jelliffe16 Standard used might be too high for this area. In earlier study conducted in the area decades ago by Omolou, Jegede and Osifo ${ }^{18}$ though based on a smaller sample made similar conclusion. However highest percentage (72\%) of undernourished children were found in PEM group.

The Non-significant differences in mean values of Height, Weight, Upperarm circumference, triceps skinfold and subscapular skinfold between normal and others shows that in the present study these anthropometric variables were not significantly affected by other type of malnutrition. Whereas the significant differences between normal and PEM indicate that, these variables were seriously affected by EPM. It therefore shows that these measurements can be sued singly or in combination in the diagnosis of EPM in this group.

The sensitivity of each of the parameters however, appears to vary between the groups and within the same group (Tables 4-7). The variables are also inter-related. This interrelationship changed with the nutritional status. While there was perfect relationship between them in Normal, these changes considerably in PEM group (Tables 10 and 11) perhaps due to gross disturbance in body composition. Correlations were intermediate in others, probably due to much lesser change in body composition in that group. This gradation might have also been responsible for more correct anthropometric diagnosis in PEM group, intermediate in 'Others' and may be wrong in largest number of cases in 'Normal' group. The relative sensitivity of each parameter also varied with groups. All parameters were useful in making diagnosis of PEM while the most sensitive one was Triceps Skinfold. These findings are in supports of earlier studies in this field. For example, that of Ramnath and Krishnamachari ${ }^{19}$ who found PEM occurring more frequently from normal nutrition to grade II under nutrition based on Fat Fold at Triceps (FFT) measurements. Also earlier a critical review of Haider and Haider ${ }^{20}$ of various methods for assessing protein-calorie malnutrition (though) they highlighted that all the tests were found lacking in sensitivity but specificity body-composition analyses and functional tests were suggested to hold the promise of greater applicability. The largest number of misdiagnosis in Normal based on Triceps skinfold again brings out the point that the standard used may be quite unsuitable for the group. There is need for the development of local standard in that International standard may be making a large number of children as Protein Energy Malnourished. This observation was raised also by Hamil et al. ${ }^{21}$ where they found the commonly used anthropometric measurements (height, weight, triceps skinfold thickness, subscapular skinfold thickness, arm circumference, arm muscle circumference and arm muscle area) for standard which are usually based on a large nutritional study of predominantly white children as too high for non-white children due to lack of accepted standards when in actual fact racial and ethnic differences in normal body composition have been documented.

\section{CONCLUSION}

Based on the findings of this study, it is concluded that Triceps skinfold is the most sensitive anthropometric indicator for diagnosis of PEM in the study population and this can be used other resource restricted settings or developing countries. This supports the hypothesis that energy deficiency may be a more predominant factor in the causation of PEM in Nigeria.

\section{ACKNOWLEDGEMENT}

We thank the staff of the University College Hospital-Ibadan and the mothers of children that participated in this study for their supports.

\section{CONFLICT OF INTEREST}

The authors declare no conflict of interest.

\section{ABBREVIATIONS}

PEM: Protein Energy Malnutrition; FAO: Food and Agriculture Organization; WHO: World Health Organization; WT: Weight; HT: Height; UAC: Upper-arm Circumference; TSFT: Triceps Skinfold Thickness; SUBSCA: Subscapular.

\section{REFERENCES}

1. Murray CJL, Lopez AD. Global mortality, disability and the contribution of risk factors: Global Burden of Disease Study. Lancet. 1997;349(9063):1436-42.

2. Nemer L, Gelband H, Jha P. Commission on Macroeconomics and Health. The evidence base for interventions to reduce malnutrition in children under five and school-age children in low- and middle-income countries. $\mathrm{CMH}$ working paper no WG5:11. Geneva: World Health Organization. 2001.

3. Food and Agriculture Organization (FAO) of the United Nations. Undernourishment around the world. In: The state of food insecurity in the world 2004 Rome: The WHO. 2004

4. Müller O, Garenne M, Kouyaté B, Becher H. The association between proteinenergy malnutrition, malaria morbidity and all-cause mortality in West African children. Trop Med Int Health. 2003;8(6):507-11.

5. Black RE, Morris SS, Bryce J. Where and why are 10 million children dying every year?. Lancet. 2003;361(9376):2226-34.

6. Pinstrup-Andersen P, Burger S, Habicht JP, Peterson K. Protein-energy malnutrition: Disease control priorities in developing countries. $2^{\text {nd }}$ ed. Oxford (UK): Oxford University Press. 1993;391-420.

7. Brabin BJ, Coulter JBS. Nutrition-associated disease. Manson's tropical diseases. London: Saunders. 2003;561-80.

8. Norgan GN, Bogin B, Cameron N. Nutrition and Growth. $2^{\text {nd }}$ ed. 2012:123-52 https://doi.org/10.1016/B978-0-12-383882-7.00006-4

9. Müller O, Krawinkel M. Malnutrition and Health in Developing countries. CMAJ 2005;173(3):279-86.

10. Beaton, et al. Geneva, Switzerland, World Health Organization [WHO], Administrative Committee on Coordination, Subcommittee on Nutrition. 1990;6:51.

11. Nagy E, Vicente-Rodriguez G, Manios Y, Be'ghin L, Iliescu C, Censi L, et al. Harmonization process and reliability assessment of anthropometric measurements in a multicenter study in adolescents. Int J Obes. 2008;32(S5):S58-65.

12. Lohman TG, Roche AF, Martorell R. Anthropometric Standardization Reference Manual. Human Kinetics Books. Champaign: Illinois. 1988.

13. Mueller WH, Martorell R. Reliability and accuracy of measurements. Anthropometric Standardization Reference Manual. Human Kinetics Books: Champaign. 1988;83-6.

14. FAOMHO Committee on Nutrition Joint FAOMHO Expert Committee on Nutrition, World Health Organization and Food and Agriculture Organization of the United Nations. Joint FAOMHO Expert Committee on Nutrition [imeeting held in Rome from 22 to 29 October 1957] fifth report. Geneva: World Health Organization. 1958. http://www.who.int/iris/handle/10665/40408

15. WHO. Child Growth Standards. 2018. Available from: https://www.who.int/ childgrowth/standards/tab_Ihfa_girls_p_2_5.txt;

16. https://www.who.int/childgrowth/standards/lhfa_boys_p_exp.txt.

17. Jelliffe DB. The assessment of Nutritional status of the community. WHO Mimeograph. 1966;53:271. 
18. Morley CJ, Bangham AD, Miller N, Davis JA. Dry artificial surfactant and its effect on very premature babies. Lancet. 1981;1(8211):64-8.

19. Osifo BO, Jegede IO, Omololu A. Evaluation of various methods in the detection of protein calorie malnutrition (PCM) of early childhood. Transactions of the R Soc Trop Med Hyg. 1975;69(2):221-5.

20. Ramnath T, Krishnamachari KA. Anthropometric measurements, deficiency signs and their relationship under drought conditions. Indian J Matern Child Health. 1993;4(2):42-7.

21. Haider M, Haider SO. Assessment of Protein-calorie Malnutrition. Clin Chem. 1984;30(8):1286-99.

22. Hamil PV, Drizd TA, Johnson CL, Reed RB, Roche AF. Physical growth: National Center for Health Statistics Percentiles. Am J Clin Nutr. 1979;32(3):607-29.

Cite this article : Adetunji HA, Salami GS, Fadil MSE, Zaman UT, Bakri M, Khalil M, Bushara MEO. Relative Merits of Selected Anthropometric Measurements for Detecting Protein-Energy-Malnutrition (PEM) in Children Under Five Years in a Resource Limited Setting. Int J Med Public Health. 2019;9(4):154-9. 